\title{
Uses and gratifications of mobile Internet among South African students
}

\author{
W. Chigona, G. Kamkwenda and S. Manjoo \\ Department of Information Systems \\ University of Cape Town \\ Rondebosch, South Africa \\ wallace.chigona@uct.ac.za
}

Keywords: Mobile Internet, uses and gratifications, South Africa

Received: 9 July 2008

\section{Contents}

1. Introduction

2. South African mobile phone market

3. Uses and gratifications framework

3.1 Background

3.2 Categories of motivations

3.3 Research model and questions

4. Research methodology

4.1 Research approach

4.2 Data gathering and analysis

4.3 Limitations of the methodology

5. Findings

5.1 General findings: overall mobile phone usage

5.2 General findings: mobile Internet

5.3 Uses and gratifications of mobile Internet

6. Discussion

6.1 Uses and gratifications of mobile Internet

6.2 Summary of implications

7. Conclusion and recommendations for future research

8. Acknowledgement

9. References

\section{Introduction}

Mobile Internet is a relatively new innovation. Many see mobile Internet as a way of providing for those who cannot afford the traditional means of accessing the Internet (International Telecommunications Union 2004). Although much research has been conducted on the adoption of related technologies such as mobile phone and m-commerce, little focus has been placed on mobile Internet. This is particularly true for South Africa 
(SA). There is, therefore, a lack of understanding on how and why people use the technology. The purpose of this research, therefore, was to investigate how and why people use mobile Internet. This study focused on the SA market.

The topic for the study required the authors to define the term 'mobile Internet'. Mobile Internet can best be described as a means of 'wireless access to the digitized contents of the Internet via mobile phones' (Chae and Kim 2003). When the Internet is accessed, a request is sent by an Internet browser to a Web server, which responds by sending the information to display on a screen (Beal 2006). Since voice calls and SMSs do not query Web servers, they cannot be classified as mobile Internet. There are four main ways of using mobile Internet: email, access to general information, instant messaging services, voice-over-Internet-protocol.

Mobile phones offer a wide variety of functionality, however, this research was only confined to mobile Internet functionality. This included use of the mobile Internet for communication, entertainment and information purposes. It specifically excluded $\mathrm{m}$ commerce as this is a topic on its own. In addition, the focus was on mobile Internet access that is provided by mobile phones and not other mobile devices such as PDAs. This limitation allows for the words 'mobile' and 'cell phone' to be used interchangeably.

Uses and gratification (U\&G) was used as the underpinning theoretical framework for the study. U\&G allows for investigating the motivations for consumption of media products. It is noted that there is a dearth of U\&G studies focusing on mobile Internet. The research instrument for the study was therefore based on U\&G studies on related technologies such as traditional Internet as well as mobile phones. This allowed an investigation into the gratifications obtained from using mobile Internet and the intersection of motivations for using the traditional Internet and those from using mobile telephony.

Based on the literature, this study sought to answer the following questions:

- For what purposes do people use mobile Internet?

- What gratifications are received from the use of mobile Internet?

- Are there any particular motivations in South African mobile Internet users that are different from those identified in previous studies conducted elsewhere?

To answer these questions, this study investigated the mobile Internet use experiences of University of Cape Town (UCT) students.

This research is valuable to various mobile phone market stakeholders. Manufacturers generally produce mobile phones based on their perception of what the general user may desire. According to Gilham and Van Belle (2005), a clear understanding of cell phone users' motivations is lacking. By better understanding the U\&Gs provided by mobile Internet, manufacturers will obtain a good idea of the needs of South African consumers. This would enable them to design mobile phones that better meet these needs and enhance the features most desired by customers. It is hoped that service providers in the mobile market would also find this research useful.

\section{South African mobile phone market}

The number of mobile users in Africa grew from 7,5 million to 76,8 million over a period of nine years (1994 to 2003). This represents a 58\% annual growth rate. In comparison, Asia grew by a mere $34 \%$ (LaFraniere 2005). SA, considered one of Africa's richest countries, accounted for nearly one fifth of the growth. The SA market, in particular, consisted of 
approximately 14,4 million mobile subscribers at the beginning of 2003 (South Africa.info 2003). At the end of year 2006 this figure had grown to 35,9 million mobile subscribers (The e-Business Handbook 2006).

The three main entities in the mobile industry in SA are mobile network operators (MNOs), service providers (SPs) and wireless application service providers (WASPs) (Gilham and Van Belle 2005). MNOs are responsible for the overall management of the network. The MNOs in the SA market are Vodacom (60\% market share), MTN (32\%), Cell C (8\%) and the most recently added, Virgin Mobile (The e-Business Handbook 2006). Since Virgin Mobile is a recent addition to the market, data related to its market share are not yet available. SPs are the retailers of mobile products such as mobile phones, prepaid vouchers and contracts. They are also responsible for the billing of contract subscribers. WASPs create, host and market mobile content services. WASPs are dependent on SPs and MNOs as they provide the infrastructure and customer relationship.

Mobile phone users may acquire mobile phones through either contract or prepaid (pay as you go) plans. To qualify for a contract, a customer must have a good credit record and must provide proof of income above a minimum required amount. As an example, Vodacom requires a minimum gross monthly income of R3500 (Cellucity, n.d). With some contracts, a customer pays a fixed monthly fee and may then top up with prepaid vouchers as needed.

Contracts are generally taken over a 24 month period. Three months before the end of a contract, customers are offered the option to upgrade their mobile phone (Vodacom 2006). This means that the customer acquires a new phone and consequently takes out a new contract. With contract-induced upgrades, it is likely that mobile phone users end up with functionality that may not be needed.

Although contracts offer lower rates, prepaid plans are more flexible as the customer is not locked in. It is not surprising, therefore, that prepaid packages are more common. In fact, the introduction of pre-paid subscriber packages is one reason cited for the acceleration in the mobile market (South Africa.info 2002).

\section{Uses and gratifications framework}

\subsection{Background}

$U \& G$ research has its foundation in communication research, originally focusing on motivations for choice of mass media and mass communication (Ling and Pedersen 2003). The proponents of $U \& G$ argue that the technique is suitable for studying new communication technologies. As Ruggiero (2000) puts it, since new technologies present people with an increasing number of media choices, motivation and satisfaction become even more crucial components of audience analysis. Dunn and Perse (1998) maintain that to focus fully on the social and cultural impacts of new communication technologies may be premature until we have grasped exactly how and why people are making use of these media channels.

U\&G research seeks to examine the use of audience media in the light of the users' social and psychological needs (Leung and Wei 2000). Overall, the theoretical perspective of U\&G research centres on the motives for and consequences of media use (Rubin 1985). The U\&G perspective focuses on what people do with mass media, as opposed to what mass media does to people (Klapper 1963). The central assumption for U\&G is that audiences actively participate in media selection and use (Leung and Wei 1998). The general idea is that adopters seek gratifications in technology use based upon their individual needs or 
The U\&G approach arose out of the functionalist perspective on mass media, which was first articulated during the 1940s in research on the effects of radio programmes on members of the listening audience (Eighmey and McCord 1998). Over the years the approach has been used to study the motivations for using general media applications such as the use of the Internet (Gillenson and Stafford 2004), the use of TV as well as the motivations for specific areas within the media.

The primary strength of $U \& G$ is its ability to permit researchers to investigate mediated communication situations via single or multiple sets of psychological needs, psychological motives, communication channels, communication, content and psychological gratifications within a particular or cross-cultural context (Lin 1996). Eighmey and McCord (1998) posit that the self-reported perceptions and motivations give researchers insights into the factors that attract continuing audiences to specific mass media. Furthermore, U\&G is flexible. As new communication technologies rapidly materialize, the range of possible topics for $U \& G$ research also multiplies (Ruggiero 2000). U\&G theory is robust and useful in the development of theoretical dimensions representative of consumer motivations for media use. In addition, media-specific measures developed from the U\&G framework are useful for assessing the likely uses of the media by consumers (Stafford, Stafford and Schkade 2004).

U\&G studies are either exploratory, starting off with no assumptions and seeking to identify U\&Gs of an innovation or, alternatively, the study starts off with a list of possible gratifications and seeks to confirm with the respondents whether those apply in their context (Ling and Pedersen 2003). In the latter case, the list of possible motivations is based on previous U\&G studies. Only one U\&G study on mobile Internet (Stafford et al. 2004) was identified. Moreover, there are only a few studies conducted on mobile technology using the $\mathrm{U} \& \mathrm{G}$ framework. This means that a large pool of U\&Gs to draw from does not exist. As such the initial list of U\&Gs for this study would be largely drawn from related technologies, namely the mobile phone and traditional Internet.

Past U\&G research categorizes motivations for using different media forms into several groups. Motivations for using communication technologies have often been grouped into instrumental on the one hand, and social on the other hand. McClatchey (2006) differentiates between hedonic and utilitarian motivations for using mobile phones. Cutler and Danowski (1980) as well as Stafford and Stafford (1996) divide the motivations into two categories, namely, process and content. Process motivations concern the actual use and/or enjoyment of the medium itself. In content motivation, individuals use a medium for the content that it carries. Later Gillenson and Stafford (2004) added an additional motivation categorization, namely social motivation. Social motivations include chatting, friendship, interactions and people. Stafford et al. (2004) note that there is limited evidence supporting a third and distinct social gratification for Internet use. Since this study was similar to the study of Stafford et al., the three categories identified in their study were used. In Table 1 is a summary of motivations for mobile phones, for traditional Internet as well as from mobile Internet drawn from previous studies.

Table 1 Summary of motivations for using mobile phone, traditional Internet and mobile Internet drawn from literature

\begin{tabular}{|l|l|l|l|}
\hline & Mobile phone & Traditional Internet & $\begin{array}{l}\text { Mobile } \\
\text { Internet }\end{array}$ \\
\hline $\begin{array}{l}\text { Content } \\
\text { gratifications }\end{array}$ & & $\begin{array}{l}\text { Resources } \\
\text { Searching }\end{array}$ & \\
\hline
\end{tabular}




\begin{tabular}{|c|c|c|c|}
\hline & & $\begin{array}{l}\text { Web surfing } \\
\text { Websites } \\
\text { Information } \\
\text { Research } \\
\text { Education } \\
\text { Learning }\end{array}$ & \\
\hline $\begin{array}{l}\text { Process } \\
\text { gratifications }\end{array}$ & \begin{tabular}{|l} 
Personal safety \\
Financial incentive \\
Parental control \\
Time management \\
Image/Fashion/Status \\
Privacy management \\
Dependency \\
Information access \\
Immediacy \\
Mobility \\
Pleasure \\
Reassurance \\
Escape \\
Relaxation \\
Inclusion
\end{tabular} & \begin{tabular}{|l|} 
Speed \\
Clarity of purpose \\
Purchase interest \\
Personal involvement \\
Personal interest \\
Interactions \\
People \\
Controversy \\
Technology
\end{tabular} & $\begin{array}{l}\text { Accessibility } \\
\text { Ease of use } \\
\text { Efficiency } \\
\text { Instant } \\
\text { Productivity } \\
\text { Quickness } \\
\text { Simplicity } \\
\text { Usability }\end{array}$ \\
\hline Social gratifications & Social interaction & $\begin{array}{l}\text { Friends } \\
\text { Chatting } \\
\text { Continuing } \\
\text { relationship }\end{array}$ & $\begin{array}{l}\text { Keeping in } \\
\text { touch }\end{array}$ \\
\hline
\end{tabular}

\subsection{Categories of motivations}

\subsubsection{Process motivations}

One of the most cited process motivations for mobile phone is personal safety. In a study on college students' mobile phone usage, Aoki and Downes (2003) noted that personal safety was one of the initial motives for having a mobile phone. Most respondents in Aoki and Downes study stated that personal safety in the case of a car emergency was their initial motive to have a mobile phone. Respondents also indicated that mobile phones give them psychological security when they are out at night.

Financial incentives havealso been cited as a motivation for using mobile phones.In the USA there is a perception that using mobile phones to make long-distance calls is cheaper than using landline phones (Aoki and Downes 2003). The context in SA is different. However, set-up costs of acquiring a mobile phone (especially one with Internet capabilities), could be investigated to see if there are any hindrances to the use of mobile Internet. In some societies, a mobile phone is used as a status symbol (Aoki and Downes 2003; Katz and Sugiyama 2005). A number of studies have found that people, especially the youth, use mobile phone to enhance image/status. A mobile phone is perceived as a fashion accessory in the same way as jewellery. Leung and Wei (2000) also identify fashion/status motives among pager users.

Dordick, Jesuala and Williams (1985) as well as O'Keefe and Sulanowski (1995) identify entertainment or fun as a major motivation in the use of the telephone. Examples here are downloading of movies, or playing music. Mobile phones could also be used as a means of escaping from reality (Barbato, Perse and Rubin 1988). Sometimes people browse through their mobile phone just to avoid contact with other people. Mobile phones are also used for privacy management; i.e. mobile phone users decide who to give the mobile phone number 
and who to give the fixed line number. In the study conducted among American college students it was found that several respondents use landlines numbers for certain business transactions and only keep mobile phone numbers for those who are in-group members (Aoki and Downes 2003). A study among pager users found that management of calls was a strong motivation (Leung and Wei 1998).

Dependency has also been identified as a motivation for mobile phone usage. Aoki and Downes (2003) state that as participants start using mobile phones regularly, it becomes part of their lives and they feel lost without it.

People also use mobile phones for time management; that is to more efficiently use their time either by storing important appointments, getting quick information or as an organizer (Aoki and Downes 2003; Dimmick, Patterson and Sikand 1994; Leung and Wei 2000).

Other process motivations identified include access, social interaction and parental contact. Leung and Wei (2000) identify mobility, immediacyand fashion/status as motivations among mobile phone users. In a study on how ordinary people used phone technology during the 9/11 attacks in New York, it was found that the mobile phone allowed intensive immediacy (Katz and Rice 2002). In a study in interpersonal communication motives, six motives were identified, namely pleasure, affection, inclusion, escape, relaxation and control (Rubin et al. 1988). O'Keefe and Sulanouwski (1995) contend that all these interpersonal motives, with the exception of affection and control, could be extended to mass media situations.

The only available U\&G study on mobile Internet to date was conducted by Stafford et al. (2004). The study found that speed, ease and convenience are the main motivations among a sample of executive MBA students in the United States.

\subsubsection{Content motivations}

Aoki and Downes (2003) found that the use of mobile phones to access the Internet for information is not preferred. However, the study shows that European countries and Japan make greater use of mobile Internet for information than Americans. Rubin (1981) and Leung and Wei (1998) also identify information access as a motivation.

\subsubsection{Social motivations}

Eighmey and McCord (1998) investigated audience experience of commercial Websites. They discovered new dimensions such as personal involvement and continuing relationships as the most important motivators in the use of the Internet.

Table 2 provides a summary of the different motivations that were identified in previous studies in mobile and similar technologies.

Table 2 Overview of previous U\&G studies

\begin{tabular}{|l|l|l|l|}
\hline Author(s) & $\begin{array}{l}\text { Research } \\
\text { areas }\end{array}$ & $\begin{array}{l}\text { Research } \\
\text { methods }\end{array}$ & Motivations identified \\
\hline $\begin{array}{l}\text { O'Keefe and } \\
\text { Sulamowski } \\
1995\end{array}$ & Telephone & Qualitative & $\begin{array}{l}\text { Entertainment, social, acquisition, } \\
\text { time management }\end{array}$ \\
\hline $\begin{array}{l}\text { Leung and Wei } \\
1998\end{array}$ & Pager & Quantitative & $\begin{array}{l}\text { Fashion/status, sociability, } \\
\text { entertainment, information seeking, } \\
\text { utility }\end{array}$ \\
\hline $\begin{array}{l}\text { Leung and Wei } \\
2000\end{array}$ & $\begin{array}{l}\text { Mobile } \\
\text { phone }\end{array}$ & Qualitative & $\begin{array}{l}\text { Fashion/status, affection/sociability, } \\
\text { relaxation, mobility, immediacy, }\end{array}$ \\
\hline
\end{tabular}




\begin{tabular}{|c|c|c|c|}
\hline & & & instrumentality, reassurance \\
\hline $\begin{array}{l}\text { Aoki and } \\
\text { Downes } 2003\end{array}$ & $\begin{array}{l}\text { Mobile } \\
\text { phone }\end{array}$ & $\begin{array}{l}\text { Qualitative + } \\
\text { quantitative }\end{array}$ & $\begin{array}{l}\text { Personal safety, financial incentive, } \\
\text { information access, social interaction, } \\
\text { parental contacts, time management, } \\
\text { dependency, image, privacy } \\
\text { management. }\end{array}$ \\
\hline $\begin{array}{l}\text { Stafford et al. } \\
2004\end{array}$ & Internet & $\begin{array}{l}\text { Qualitative + } \\
\text { quantitative }\end{array}$ & $\begin{array}{l}\text { Resources, search engine, searching, } \\
\text { surfing, technology, Website, } \\
\text { education, information, learning, } \\
\text { research, chatting, friends, interaction, } \\
\text { people }\end{array}$ \\
\hline $\begin{array}{l}\text { Eighmey and } \\
\text { McCord1998 }\end{array}$ & Internet & $\begin{array}{l}\text { Qualitative + } \\
\text { quantitative }\end{array}$ & $\begin{array}{l}\text { Purchase interest, controversy, clarity } \\
\text { of purpose, continuing relationship, } \\
\text { personal involvement }\end{array}$ \\
\hline $\begin{array}{l}\text { Gillenson and } \\
\text { Stafford } 2004\end{array}$ & $\begin{array}{l}\text { Mobile } \\
\text { Internet }\end{array}$ & $\begin{array}{l}\text { Qualitative + } \\
\text { quantitative }\end{array}$ & $\begin{array}{l}\text { Convenience, efficiency, immediacy, } \\
\text { ease of use, speed, productivity. }\end{array}$ \\
\hline
\end{tabular}

\subsection{Research model and questions}

This research aimed to test whether the motivations and gratifications identified in past studies apply to mobile Internet in the SA context. The gratifications highlighted above, on the mobile phone, Internet and mobile Internet, were combined into a model (see Table 3). Only the motivations likely to apply to mobile Internet were included. Personal safety, controversy, personal involvement and reassurance, among others, were excluded.

Table 3 Uses and gratifications identified from previous studies.

\begin{tabular}{|l|l|l|}
\hline Process & Content & Social \\
\hline Privacy management & Knowledge/research & Chatting \\
Parental contact & Information seeking & Interaction \\
Ease of use & Entertainment/fun & Friendship \\
Speed & Education/learning & Escape \\
Dependency & & \\
Search & & \\
Mobility/Convenience & & \\
Immediacy & & \\
Financial incentive & & \\
Fashion/status/image & & \\
E-mail/Info access & & \\
Surfing & & \\
Time management & & \\
\hline
\end{tabular}

\section{Research methodology}

\subsection{Research approach}

One of the aims of this research was to verify whether the U\&Gs identified in previous studies on the mobile phone and traditional Internet also apply for mobile Internet. This research was predominantly explanatory since further explanation of relationships and 
themes were being sought. However, since mobile Internet is a relatively new innovation there were a limited number of previous studies available to draw information from. Therefore, exploratory research was also required to identify possible new themes and relationships that were unique to mobile Internet.

This study was conducted using a qualitative approach. Verbal communication of the participants' feelings and experiences added value, depth and richness to the understanding of the concepts.

\subsection{Data gathering and analysis}

The data for the study were gathered using face-to-face semi-structured interviews. Each interview lasted on average 40 minutes. The questions for the interviews were derived from the themes identified in previous studies. All the interviews were recorded with the participants' permission.

A homogenous sample of fulltime university students was used. The reasons for using university students as the sample were twofold: first, convenience - it was easy for the researchers to find student respondents; second, there was a need to find people who have considerable experience of using mobile Internet. Previous studies have indicated that the youth are among the early adopters of mobile technologies (McClatchey 2006).

The sample was limited to 17 students. The selection was random as well as purposive. It was purposive in the sense that the research team tried to vary the sample in terms of programme of study, year of study, gender and race. The research team approached students on campus and inquired if they use mobile Internet; only mobile Internet users were interviewed. The next step was to decide if they met the diversity requirements.

The data collected were analysed using thematic analysis. Thematic analysis is defined as 'a method for identifying, analysing and reporting patterns (themes) within data' (Braun and Clarke 2006). First, the research team familiarised itself with the data by going through the data several times. Themes were then identified from the data; a theme identifies a feature of the data that appears to be interesting or significantly tied to the research questions. The themes were reviewed and compared between researchers and those that were not common were further explored. The joint analysis provided significant benefits as it made it possible for themes that may have been overlooked by one researcher to be picked up on by the other. Relationships between themes were identified and where applicable sub themes were created. Findings were then related to the literature for validation and conclusions and implications were drawn.

\subsection{Limitations of the methodology}

Although sampling was done randomly, the findings of this study should be generalized with caution. It is acknowledged that student samples often do not reflect the general trends in the population, therefore it is highly likely that their needs and gratifications differ from those of other users.

Another limitation of the study was its bias towards users of mobile Internet. It is acknowledged that non-adopters could have provided useful insights into the investigation. In addition, a factor that could affect the findings of this research was the assumption made that all respondents had a mobile phone. Factors such as the cost of acquiring a mobile phone, to use mobile Internet, were not considered. 


\section{Findings}

\subsection{General findings: overall mobile phone usage}

The results show that the choice of the MNOs is based on the popularity of the MNO, the reliability of the network, affordable rates as well as permanency of the phone number. The most popular MNO among the sample was Vodacom. One respondent said Vodacom was chosen because 'Vodacom is a monopoly and you just have to accept them'. Vodacom was not a monopoly. It is likely that the respondent was referring to the size and market share of the MNO. As one respondent put it, Vodacom was also perceived as the 'most reliable network in Cape Town'.

Permanency of the phone becomes relevant because some MNOs disable the phone number if a subscriber does not top up the airtime for a specified period of time. Two of the respondents claimed that they chose MTN because the MNO did not prescribe a maximum period for subscription without purchasing airtime. Both of these respondents were foreign students who travel back to their home countries during the holidays; and as such may stay without purchasing airtime for extended periods of time. One of the foreign students indicated that MTN's international calls were lower than that of its competitors.

It was noted that some respondents subscribed to multiple networks. Customers subscribe to multiple MNOs in order to take advantage of the pricing systems: In some instances, it is cheaper to call a number within the same network. So the different numbers are used to call contacts on the respective networks. In addition, some of the MNOs occasionally run offers for free calls within their network; respondents indicated an interest in taking advantage of the various offers. Customers with multiple subscriptions didn't necessarily have multiple phones, they simply had different subscriber identity module (Sim) cards which they swapped on the same hand set. However, some of the respondents had multiple handsets which were tied to different networks. Owning of multiple handsets was also reported in studies among the youth in other parts of the global (Ogunyeni 2006; Wilska 2003).

Consistent with the literature, prepaid plans were more popular than fixed contracts. Thirteen of the 17 respondents had prepaid plans. The remaining four had purchased their mobile phones on a fixed contract. In addition most contracts had the option to top up, thus making them function partially as prepaid plans.

Of the 17 respondents, eight were responsible for their own payments. The bills of the remaining four were paid by their parents or older siblings. This seemed to influence their usage to an extent. Generally a respondent used mobile Internet more if someone other than themselves was responsible for payment. This is captured by the following statement from one of the respondents: 'I don't pay it, so I don't care'

This was not the case for all respondents however. One respondent claimed that the fact that someone other than himself paid the account limited his usage.

\subsection{General findings: mobile Internet}

This study found no difference in mobile Internet usage based on gender, age or programme of study. Respondents' frequency and usage patterns were much the same. Existing research is not conclusive on the impact of gender on mobile technology usage. A study of mobile telephone use among Norwegian teenagers pointed to gender-related differences in the use of mobile telephony (Ling 2001); this is in line with earlier U\&G studies on the telephone (Dimmick et al. 1994; Noble 1987; O'Keefe and Sulanowski 1995). On the other hand, DeBaillon and Rockwell (2005) as well as Ogunyemi (2006) found no significant difference 
between the genders in having a mobile phone: male respondents use mobile Internet as much as females and for the same motivation. It can be argued, therefore, that as the technology is maturing, the impact of gender on technology use diminishes. One of the female respondents said:

'There isn't much technology in a cell phone. It's just like any other household equipment ... like using a vacuum cleaner or a toaster.'

The majority of respondents had no Internet access at home and mobile Internet was the only access they had off campus. Two respondents had Internet access at home via HSDPA and broadband. These two still used mobile Internet; one of the two respondents believed that mobile Internet was faster than HSDPA, the other found mobile Internet more convenient.

One of the respondents hinted that the convenience of the mobile Internet is that it does not require one to apply for a service from an Internet provider.

'You can get started whenever you want to, if you don't want to use it you simply leave it. I like that freedom'

Almost all respondents believed that mobile Internet is positive and had made a significant difference to their lives. The statements below reflect the responses:

'It's there, part of life....like a finger.'

'[Mobile Internet] makes life simpler.'

'Mobile Internet is probably the best thing that's come out on cell phones so far.'

'It's the future man. You got the Internet in your hand.'

\subsection{Uses and gratifications of mobile Internet}

\subsubsection{Process motivations}

\section{Financial incentive}

Financial incentives for using mobile Internet were noted in comparison to both using traditional forms of accessing the Internet and to other forms of contacting people via the mobile phone. The majority of respondents believed that mobile Internet was cheaper and more affordable than alternative Internet access methods such as dial-up connection or Internet cafés. The majority of respondents preferred mobile Internet to Internet cafés as a medium of Internet access off campus, mainly because they believed that Internet cafés are more expensive. The financial advantage of mobile Internet over cafés is its divisibility. The minimum time charged for in a café is either 15 or 30 minutes. That would be costly for simple and quick tasks like checking e-mail. As one respondent put it:

'... it's way better than going to a café ... because at the café you can't find a cheaper one like five minutes [or] 10 minutes; ... but just going to Yahoo, Google you can't spend like close to six minutes.'

Respondents indicated that they only used cafés if they would like to print documents or to access their university examination results since it was difficult to interact with and read the page via mobile Internet. One respondent would consider using Internet cafés only'if in a remote area' where there was no mobile phone coverage. Only one respondent indicated they preferred an Internet café as they liked 'the feel of the machine' and does not believe that mobile Internet is 'real enough'. However, this was an exception.

Mobile Internet was seen as more affordable than sending SMS or calling. The majority of 
respondents stated that they preferred to chat online rather than to send an SMS or to call. Chatting 'just costs a few cents'. A respondent sent free SMSs from the Internet via a mobile phone.

'You see, I may spend 80 Cents to send SMS ordinarily, but if I use the cell phone to send SMS, I just go to Vodacom Website and send an SMS and spend 1 or 2 cents to send the same SMS ... So it's cheaper ... Many people also use this method.'

One of the international students also sent Web-based free SMSs to family and friends back home in Mauritius.

'... so I log onto a Website, it's a cell phone provider's website from Mauritius ... and I send an SMS to Mauritius.. . It's free ... am paying like 2 cents just for connection from the cell phone to the Internet.'

Mobility, convenience and immediacy

Mobility and convenience are main motivators for the use of mobile Internet. Almost all respondents indicated that the convenience and mobility of mobile Internet appealed to them, making it the main motivator for using mobile Internet. When respondents were asked: 'What do you like most about mobile Internet?' the most common response was 'convenience and mobility' and that'you can do it anywhere at any time'. Here are some of their comments:

'Cause I don't have a computer, I think the mobile one is very mobile, like go there all the time, any minute I wanna use it, so I think the mobile phone one is very good.'

'It [mobile Internet] helps out with time management and convenience ... things are more accessible now than before, like information, if I do need it, I can be like anywhere and be able to get information.'

'With me it's convenience. It's cheaper, It's I think 12 cents, rather than driving to campus or to an Internet café. And if am on holiday, it's easier for me to check my mail rather than coming all the way here. I mean it's cheaper.'

This characteristic of mobile Internet is inherent and unique and is what differentiates mobile Internet from more traditional access methods.

\section{Time management}

The issue of time management was addressed from two angles: (a) the impact of mobile Internet on time management; and (b) the use of online calendars and organizers. There were mixed responses regarding the impact of mobile Internet on efficiency. For some, mobile Internet provided them with the ability to download academic materials and access e-mail spontaneously, thereby resulting in greater efficiency. A respondent noted that before going to campus to download course material from the Website, they first checked via mobile Internet whether the material was available; thus avoiding wasting time. The main argument against the role of mobile Internet in saving time was that it takes up time that could be better utilized and hence does not make the users more efficient. It can therefore be said that there was no conclusive evidence that mobile Internet helped the respondents to manage time more efficiently.

The use of online calendars and organizers was not common among the respondents. The majority preferred, instead, using the calendar on their phones. Only one respondent used the university online organizer via a mobile phone. 
Almost all the respondents believed that it was trendy and fashionable to have and to use an Internet enabled phone. Half of the respondents did not agree that an Internet enabled phone elevates their status or image in any way. They perceived Internet enabled phones to be more of a norm and standard on phones than a distinguishing factor. The other half believed that an Internet-enabled phone elevated their image and status. They believed that it is the 'in thing', keeps the user 'in touch with the generation' and they would be 'embarrassed' if they did not have the functionality.

Almost all respondents selected their phone specifically because it had Internet functionality. The main motivation for the choice was to gain access to online chat and e-mail

functionality. One respondent, however, expressed that they chose an Internet-enabled phone 'not because I want it but because I just need to have it. Else, what's the point?' Furthermore, many respondents admitted that peer pressure was an important factor in selecting an Internet-enabled phone.

\section{Accessing e-mail}

Ten of the respondents used mobile Internet to access e-mail. According to the respondents, this was a critical use of mobile Internet. They checked their e-mail at least once a day when off campus. They claimed that being able to check their e-mail spontaneously made them more efficient.

Those who didn't use the mobile Internet to access e-mail indicated that they would like to use the functionality but couldn't due to its complexity. Many of them didn't know how email on the mobile phones work. One respondent stated that it was extremely difficult to set up e-mail on a mobile phone and just as difficult to use it. The respondent also found it slow and prefers accessing e-mail from a home personal computer (PC). The respondent also expressed that it was easier to read on the big screen of a PC. Difficulty in downloading email attachments was also cited as a hindrance in using mobile Internet for accessing e-mail.

\section{Search capability or general browsing or surfing}

This was a recurring theme across the interviews. Generally, respondents browse or surf when they were bored or wanted to waste time. In traditional Internet use, the process dimension of Internet gratification usually involved a large search component (Stafford et al. 2004). The findings also show that searching was popular among mobile Internet users. However, the findings of this study show that most of the searches were short, such as word definitions as illustrated by one respondent:

'If you have a word or something you wanna find out that you don't know... it's very easy to ... "Google define" it gives you quite a good explanation. It's very useful on your cell phone 'course it's obviously on the go when you don't have always a computer with you, so I found that very useful as well.'

\section{Parental contact}

The use of mobile Internet to keep in touch with parents was not common. Only three of the respondents indicated that they used the mobile phones to e-mail their parents. One respondent indicated that he communicated with his father via SMSs through mobile Internet and also indicated that he chats with the father using Opera Mini. However, none of the respondents used mobile Internet to chat with their parents. In fact, they were horrified at the very idea of chatting with parents online. The reason cited was that online chatting was not considered an appropriate communication channel for parents. They instead preferred using the more traditional features of mobile phones (such as sending SMS or calling) to contact parents. However, respondents used mobile Internet to chat with relatives within the same age group. 


\section{Dependency}

Previous studies showed that dependency is a key motivator in mobile phones usage. The findings of this study confirm this. Nine of respondents indicated that they would feel disadvantaged and disconnected without mobile Internet. However, only five said they are reliant and dependent on mobile Internet. Most respondents used mobile Internet everyday and in some cases 'buy airtime just to access the net'. Some respondents admitted to using mobile Internet many times a day and for long periods of time; up to five hours. One respondent declared that he 'can't do without it'. Another indicated that it would be difficult without mobile Internet because it 'has become a routine'. This may indicate a general sense of dependency.

However, while all acknowledged that they would feel disconnected without mobile Internet; very few suggested that they were addicted to mobile Internet. Nevertheless, a strong sense of dependency was apparent among the respondents.

\subsubsection{Content motivations}

All respondents indicated that they used mobile Internet to seek information. The types of information sought differed.

\section{General browsing}

Mostly, respondents used mobile Internet for general browsing and research purposes. Respondents indicated that they browse for information if they need to or they were bored. Information sought included material for their assignments or projects, specific information such as the meaning of words, or just checking the weather. This is illustrated by the following statements:

'[I use it] mainly to check up weather report.'

'At one point I had to search, I didn't know the meaning of some words.'

'When you go to Vula_searching ... like for an assignment for example then you go and Google for it and you get it'.

Sports Websites were also popular especially among the male respondents. One of the respondents indicated that he regularly checks cricket news. Another respondent said:

'... if there is a soccer match playing ... I go to some Website to check the live scores, what's happening. I refresh that page quite a lot of times to see what's happening, how the score are updating.'

One respondent regularly checks financial markets for his father and then phones him with the details.

\section{Education or learning}

The most common use of mobile Internet for educational purposes is downloading lecture notes and other academic information. Much emphasis was placed on the importance of being able to download course notes. One respondent stated that they would be 'lost without it'. Another respondent expressed the need to download notes but faces difficulty in doing so as he cannot access the UCT Website. As one respondent explained, students download the notes from the respective course Web pages to their mobile phones, the documents are then transferred to a computer; in essence using the mobile phone as an intermediary device.

One respondent used the mobile Internet to access the university library site, reserve and renew books, and check if ordered books had arrived. This can be classified as the use of the Internet to perform academic supportive activities. 
Some respondents mentioned difficulty in accessing the university Website, particularly to check their examination results. This is due to compatibility issues; some mobile browsers are not able to download certain pages. Two respondents indicated they downloaded Opera Mini, a mobile phone Web browser that displays almost any Web page, including the university's Website.

\section{Research or knowledge}

The majority of respondents used mobile Internet for research purposes; this was usually related to academic work. This was one of the main uses of mobile Internet and in some cases the only reason some respondents used mobile Internet.

\section{Entertainment}

Respondents indicated that they used mobile Internet for entertainment purposes.

Entertainment material mostly downloaded by respondents included ring-tones, music and wallpapers or pictures. Less downloaded material included themes, games and video clips. Some respondents did not download any entertainment material mainly because of the high costs. These respondents were aware that there are free sites but did not know them. Another reason expressed by one respondent was that 'the quality [of materials from free sites] is not that great'. Another respondent also indicated that he plays games online.

\subsubsection{Social motivations}

\section{Online chatting}

Online chatting emerged as the main motivator for mobile Internet use among the respondents. Fourteen of the respondents used online chat services. Most of the respondents acquired an Internet-enabled mobile phone specifically for this reason.

Respondents expressed their preference for online chatting over SMS or calling. According to the respondents, this is primarily because chatting is a much cheaper alternative; and it is perceived to be more uninterrupted and yields an instant response. Some respondents also claimed that the chatting service is simple and easy to use.

The most popular chatting service among the respondents was MXit, a popular SA mobile instant messaging service. Most of the respondents chatted many times a day, every day for anything from three to five hours at a time. One of the respondents indicated that:

'I log in [MXit] like during the night not just all the time but I don't sleep without going to MXit'.

In response to the question of how often they used Internet chat room services, one respondent said:

'Oh God! Do you wanna know how many hours a day?...everyday definitely... probably around $4 \mathrm{~h} 00$ or $5 \mathrm{~h} 00$ '.

Four respondents didn't chat online. Two of the respondents indicated that they didn't chat because they find MXit difficult to use. One respondent said:

'I no longer use it ... [because] everybody started using it and they are using it for wrong reasons so I think I am not in that category ... I used to use it because I wanted to communicate with my friends because it is cheaper, but now when people see you there they associate you with wrong things thinking you participate in such things. So no, I stopped; I don't want to be part of that.' 
The 'wrong things' in the quotation is making reference to the negative publicity MXit has had in the local media (Chigona and Chigona 2008). According to the existing literature, there is limited evidence in support of a social motivation such as chatting. The findings of this study show that chatting is perhaps the most popular use of mobile Internet among the SA youth.

\section{Maintaining relationships}

Related to chatting are the motivations of maintaining friendships and interactions. The respondents chatted online mainly to keep in contact with friends. Most respondents saw chatting as a 'good way of communicating' with friends. Respondents claimed that chatting allows them to maintain and build relationships with friends. Many stated that these services allow them to chat to friends who are not in the same city or who they don't see often.

\section{Avoidance or escape}

Eight respondents indicated that they used mobile Internet, in particular online chatting, to avoid direct contact with people. The respondents claimed that they did this because it was much easier to confront people without having to directly face them. The respondents also indicated that they used mobile Internet as a means of escape. They sometimes did this because they '[didn't] feel like talking'. This finding is in accordance with the literature.

\section{Discussion}

\subsection{Uses and gratifications of mobile Internet}

The study confirmed that there are process, content as well as social motivations for using mobile Internet. Other than time management and parental contact, all the other factors were confirmed.

\subsubsection{Process motivations}

From the earlier U\&G research on the television to the more recent ones on the Internet and mobile technologies, process motivations have always been the key motivators in the use of those technologies (Aoki and Downes 2003; Gillenson and Stafford 2004; Leung and Wei 2000; Rubin 1981). The findings of this study confirm the literature to an extent. There is strong evidence of dependency, convenience, mobility, financial incentive and 'Googling'orsearch as process motivations among mobile Internet users. No strong evidence was found to indicate that parental contact is a motivator among the respondents.

There is also inconsistency about fashion or status as a gratification for some users. Most of the respondents believed that it is fashionable to have an Internet-enabled phone, but this does not affect status in any way. Similarly, there was a degree of inconsistency regarding time management and information access or e-mail as motivators, thus making it difficult to confirm or refute fashion or status, time management and e-mail as motivators. However, if the negative issues surrounding e-mail could be addressed, it is likely that it would be an important motivator.

\subsubsection{Content motivations}

This study confirms the literature that content motivations are important in Internet usage (Aoki and Downes 2003; Gillenson and Stafford 2004; Leung and Wei 2000; Rubin 1981; Stafford et al. 2004). There is clear indication that content-based motivations exist for mobile Internet use. 
the most notable distinction in their exploratory analysis of Internet-based mobile device $\mathrm{U} \& \mathrm{G}$, as compared to traditional Internet use, is the lack of any specific content-based motivation for device use. They conceded, though, that such contrasting findings may be due to their sample consisting of executive MBA students who were more business driven.

These motivations appear to be related to some process motivations. Further studies will be required to measure such relationships and the degree to which the content motivations are related to process motivations.

\subsubsection{Social motivations}

Recent studies provide limited evidence in support of a third and distinct social gratification for Internet use (Stafford and Stafford 19982001 cited by Stafford et al. 2004). Stafford et al. (2004) validated this emerging type of Internet gratification. This study found the existence of social gratifications in mobile Internet use. In line with the literature, this study showed that there was undoubtedly a social dimension to mobile Internet use, at least among university students. In fact, it may have been the strongest of the three motivations.

While no revisions to the list of the existing social motivators are necessary, further studies are required to determine the degree to which the social motivations relate to, or depend on, process and content motivations.

\subsection{Summary of implications}

The findings of this study confirmed the motivations that had been identified in other U\&G studies in other parts of the world. Not only did this study confirm the existence of social motivations in mobile Internet, it also indicated that these motivations could be just as important as process motivations.

There is a need to further investigate the relationship between these motivations. For instance, dependency was identified as a main motivator in almost all respondents. Despite being a process motivator, dependency is, in more cases, related to chatting. Respondents were dependent on mobile Internet partly because they wanted to chat online. A large portion of respondents' time online was spent chatting. Another important factor is the use of search engines. Although Stafford et al. (2004) categorized search engines as Internet functionality and therefore a process motivator, it appears that the use of search engineswas rather for specific knowledge or information seeking purposes, thus leading to it being an important content motivator too.

One of the propositions of this study was that the U\&Gs for mobile Internet are, in fact, an intersection of U\&Gs for traditional Internet and the U\&Gs of mobile phone. This preposition has been confirmed. Mobile Internet $U \& G$ are predominantly derived from mobile phone gratifications and Internet gratifications. Figure 1 illustrates this intersection of motivations.

Figure 1 Intersection of mobile phone, traditional Internet and mobile Internet motivations 


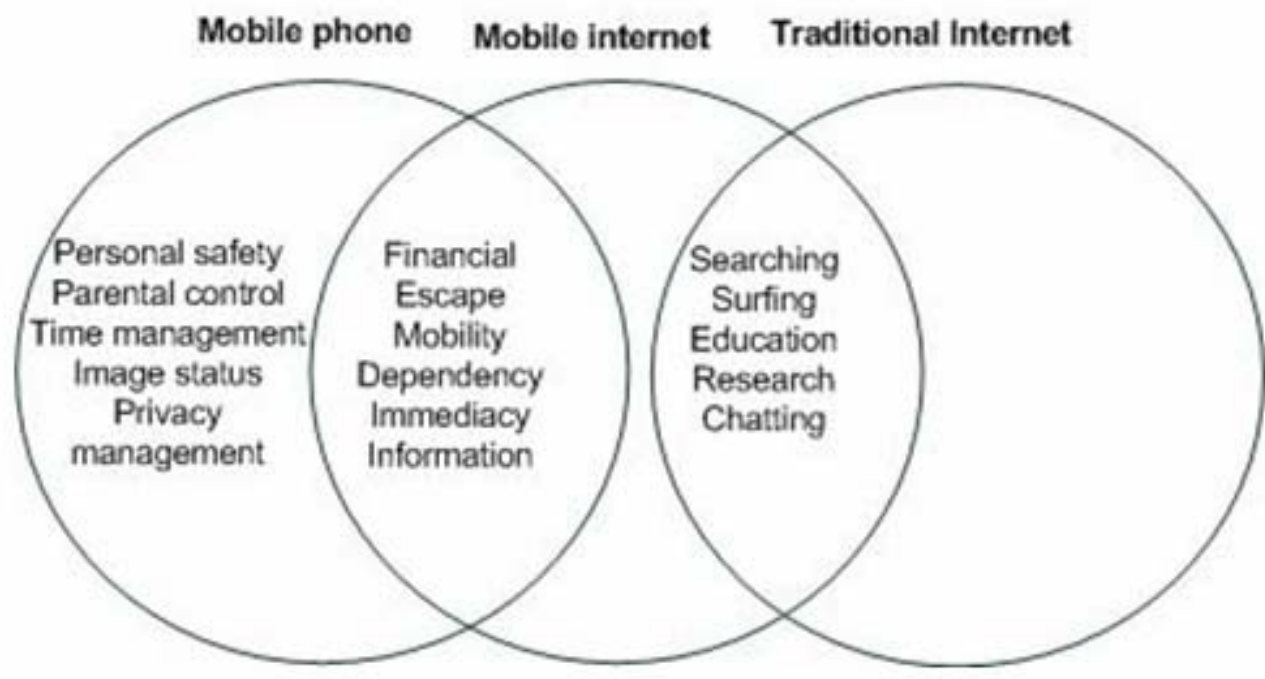

$\underline{\text { top }}$

\section{Conclusion and recommendations for future research}

There has been a significant increase in the diffusion of cell phones in SA and much of the world. Cell phone technology has advanced rapidly and continues to do so. The cell phone has become one of the most important communication, social, business and entertainment devices of the 21 st century. The purpose of this study was to understand mobile Internet in the SA context. U\&G framework was used to identify how and why people use mobile Internet.

There is a large degree of consistency between the motivations identified in this study on the one hand and those identified in previous U\&G studies on newer technologies. The findings confirm the existence of process and content motivations among mobile Internet users. In addition, the study found much evidence to support the contended theory that social motivations exist for mobile Internet use. In fact, social motivators, such as online chatting, were the strongest of the three.

It also emerged that mobile Internet was the preferred medium of Internet access and in some cases; it was the only medium available. This leads to the belief that mobile Internet is a very likely tool that can be used to bridge the digital divide in SA by providing Internet technologies to disadvantaged people.

Finally, this study showed that mobile Internet was being widely used and was the preferred Internet access medium among respondents. Thus, there is evidence to support the theory that mobile Internet can narrow the domestic digital divide. However, the sample was too small to generalize these findings. Perhaps, research can be conducted to validate this theory further. It would be interesting to investigate the penetration rate of mobile Internet in rural areas, as these areas are perhaps the most disadvantaged in Internet access.

\section{Acknowledgement}

This paper is a significantly revised and extended version of the paper by W. Chigona, G. Kamkwenda and S. Manjoo entitled 'The uses and gratifications of mobile Internet among the South African students', presented at the PICMET conference in 2008 in Cape Town, South Africa. 


\section{References}

Aoki, K. and Downes, E.J. 2003. An analysis of young people's use of and attitudes toward cell phones. Telematics and Informatics 20(4):349-364.

Barbato, C.A., Perse, E.M. and Rubin, R.B. 1988. Conceptualization and measurement of interpersonal communication motives. Human Communication Research 14: 602-628.

Braun, V. and Clarke, V. 2006. Using thematic analysis in psychology. Qualitative Research in Psychology 3: 77-101.

Cellucity. (n.d.). Vodacom monthly contracts. Available:

http://www.cellucity.co.za/contractspecials.htm. [Accessed 3 April 2007].

Chae, M. and Kim, J. 2003. What's so different about the mobile Internet? Communications of the ACM 46(12):240-247.

Chigona, A. and Chigona, W. 2008. A critical discourse analysis on media about MXit by employing Habermasian validity claims. In: Proceedings of the Annual Conference on World Wide Web Application.

Cutler, N.E. and Danowski, J. A. 1980. Process gratification in aging cohorts. Journalism Quarterly 57, 269-277.

Debaillon, L. and Rockwell, P. 2005. Gender and student-status differences in mobile telephone use. International Journal of Mobile Communications 3(1):82-98.

Dimmick, J.W., Patterson, S.J., and Sikand, J. 1994. The gratifications of the household telephone. Communication Research 21:643-663.

Dordick, H., Jesuala, H. and Williams, F. 1985. Focus group and questionnaire development for exploring attitudes towards telephone service. In: Williams, F. Social research and the telephone. Los Angeles: Herbert Dordick and Associates.

Dunn, D.G. and Perse, E.M. 1998. The utility of home computers and media use: implications of multimedia and connectivity. Journal of Broadcasting \& Electronic Media 42: 435-456.

Eighmey, J. and McCord, L. 1998. Adding value in the information age: Uses and gratifications of sites on the World Wide Web. Journal of Business Research 41:187-194.

Gilham, C. and Van Belle, J.P. 2005. Factors affecting the adoption of mobile content services amongst youth in the Western Cape, SA.In: Proceedings of the 4th International Business Information Management Conference (IBIMA), 5-7th July 2005, Lisbon; Portugal.

Gillenson, M.L. and Stafford, T.F. 2004. Motivations for mobile devices: uses and gratifications for m-commerce. In: Proceedings of the Third Annual Workshop on HCI Research in MIS, 70-75, Washington, D.C.

International Telecommunication Union (ITU). 2004. Africa: the world's fastest growing mobile market. Available: http://www.itu.int/newsarchive/press_releases/2004/04.html [Accessed 2 April 2007]. 
Katz, J.E. and Rice, R.E. 2002. The telephone as a medium of faith, hope, terror, and redemption: America, September 11. Prometheus 20(3):247-253.

Katz, J. and Sugiyama, S. 2005. Mobile phones as fashion statements: the co-creation of mobile communication's public meaning. In: Ling, R and Pedersen, P. (eds.). Mobile communications: re-negotiation of the social sphere. Surrey, UK: Springer.

Klapper, J.T. 1963. Mass communication research: an old road resurveyed. Public Opinion Quarterly 27: 515-527.

LaFraniere, S. 2005. Cellphones catapult rural Africa to 21st century., Available: http://www.nytimes.com/2005/08/25/international/africa/25africa.html?ex $=1282622400 \&$ en $=32 \mathrm{~b} 49363$ eac $57 \mathrm{aae} \& \mathrm{ei}=5090 \&$ partner $=$ rssuserland\&emc $=\mathrm{rss}$ [Accessed 15 March 2007].

Leung, L. and Wei, R. 1998. The gratification of pager user: sociability, information-seeking, entertainment, utility, and fashion and status. Telematics and Informatics 15: 253-264.

Leung, L. and Wei, R. 2000. More than just talk on the move: uses and gratifications of the cellular phone. Journalism \& Mass Communication Quarterly 77(2): 308-320.

Lin, C.A. 1996. Looking back: the contribution of Blumber and Katz's uses and mass communication to communication research. Journal of Broadcasting \& Electronic Media 40:574-581.

Ling, R. 2001. "We Release Them little by little": maturation and gender identity as seen in the use of mobile telephony. Personal and Ubiquitous Computing 5:123-136.

Ling, R., and Pedersen, E. 2003. Modifying adoption research for mobile Internet service adoption: cross-disciplinary interactions.In: Proceeding of the 36th Hawaii International Conference on System Sciences. Hawaii: The Computer Society.

McClatchey, S. 2006. The consumption of mobile services by Australian University Students. International Journal of Mobile Marketing 1(1).

O'Keefe, G.J. and Sulanowski, B.K. 1995. More than just talk: uses, gratifications, and the telephone. Journalism \& Mass Communication Quarterly 72(4):922-933.

Ogunyemi, M. 2006. Consumption and (in)appropriate use of mobile phone among teenage Africans in the UK. In: Proceedings of the2nd International Conference on Pluridisciplinary Perspectives on Child and Teen Consumption.

Rubin, A.M. 1981. An examination of television viewing motivations. Communication Research 8 (April):141-165.

Rubin, A.M. 1985. Uses and gratifications: quasi-functional analysis. In: Dominick, J. and Fletcher, J. (eds.), Broadcasting research methods. Boston: Allyn and Bacon.

Ruggiero, T.E. 2000. Uses and gratifications theory in the 21 st century. Mass Communication \& Society 3(1):3-37.

South Africa.info 2002. Burgeoning telecoms market. Available: http://www.southafrica.info/doing_business/economy/key_sectors/telecoms.htm [Accessed 5 April 2007]. 
South Africa.info 2003. South Africa's telecommunications. Available:

http://www.southafrica.info/doing business/economy/infrastructure/telecoms.htm [Accessed 25 March 2007].

Stafford, M.R. and Stafford, T.F. 1996. Mechanical commercial avoidance: a uses and gratifications perspective. Journal of Current Issues and Research in Advertising 18(2):2738 .

Stafford, T.F., Stafford, M.R. and Schkade, L. 2004. Determining uses and gratifications for the internet. Decision Sciences 35(2):259-288.

The e-Business Handbook. 2006. The E-Business handbook: the review of innovation at work in South African business. Cape Town, South Africa: Trialogue.

Vodacom. 2006. Vodacom Group surpasses 21 million customer mark. Available: http://www.vodacom.com/vodacom/mccomcrdetail.do? id=438\&action=detail, [Accessed 11 April 2007].

Wilska, T. 2003. Mobile phone use as part of young people's consumption styles. Journal of consumer policy 26(4):441-464. 